\title{
A vivência de cuidadores/as de doentes de câncer: impactos, desafios e estratégias de enfrentamento
}

\section{The career's experience of a cancer patient: impacts, challenges and coping strategies}

Ana Paula de Lima Eugenio ${ }^{1}$, Luciana Elisabete Savaris ${ }^{2}$

1. ORCID: https://orcid.org/0000-0003-4451-4719 Graduação em Psicologia. Faculdades Pequeno Príncipe, Curitiba, Paraná, Brasil. E-mail. anapaula-lima2007@ hotmail.com

2. ORCID: https://orcid.org/0000-0002-7408-1187 Mestre em Saúde Coletiva. Faculdades Pequeno Principe e Universidade Federal do Paraná, Curitiba, Paraná, Brasil. E-mail profelusavaris@gmail.com

CONTATO: Nome do autor correspondente : Ana Paula de Lima Eugenio Endereço: Rua Antonio Osni Rocha 118 Cajuru Curitiba ParanáTelefone: 41 991891224. E-mail: anapaula-lima2007@hotmail.com

RESUMO Uma doença grave como o câncer, não afeta apenas a pacientes, mas muda a vida de todas as pessoas a sua volta. Geralmente, familiares assumem o papel de cuidadores/as, muitas vezes experimentam importantes mudanças em sua rotina, que repercutem na qualidade de vida e saúde mental. O objetivo desse estudo foi o de compreender a vivência de cuidadores/as de pessoas enfermas de câncer. Trata-se de uma revisão integrativa de literatura. Evidenciou-se a predominância de mulheres neste papel, o fato de que a escolha do cuidador/a nem sempre resulta de uma negociação entre familiares, que o cuidado na maioria das vezes é centralizado em uma única pessoa, assim como que a sobrecarga predispõe a um risco aumentado para quadros relacionados ao sofrimento mental. O uso de recursos espirituais/religiosos, assim como o apoio recebido por equipes de saúde foram as estratégias mais apontadas para o enfrentamento dessa vivência por cuidadores/as.

DESCRITORES: Cuidadores. Neoplasias. Adaptação Psicológica. 


\begin{abstract}
A serious illness like cancer not only affects the patients, but changes the lives of everyone around them. Generally, family members assume the role of caregivers, often experience important changes in their routine, which affect quality of life and mental health. The aim of this study was to understand the experience of the caregivers of a cancer patient. This is an integrative literature review. The predominance of women in this role was evidenced, the fact that the choice of the caregiver does not always result from a negotiation between family members, that care is most often centralized in a single person, as well as that the burden predisposes to an increased risk for conditions related to mental suffering. The use of spiritual/religious resources, as well as the support received by health teams were the most indicated strategies for coping with this experience by caregivers.
\end{abstract}

DESCRIPTORS: Caregivers. Neoplasms. Adaptation, Psychological. 


\section{INTRODUÇÃO}

o câncer se caracteriza por um crescimento desordenado de células no organismo. Dividindo-se rapidamente, estas células agrupam-se formando tumores, que invadem tecidos e podem se alastrar se para órgãos vizinhos e até distantes da origem do tumor causando o que é chamado de metástases. O câncer é provocado por mutações que alteram a estrutura genética do Ácido Desoxirribonucléico das Células (DNA).

Culturalmente temido pela sociedade, a revelação do diagnóstico apresenta-se, como uma má notícia, pelo temor do prognóstico e devido ao estigma que traz consigo ${ }^{2}$. As neoplasias se destacam como principal problema de Saúde Pública no mundo e já estão entre as quatro principais causas de morte antes dos 70 anos de idade. Em uma estimativa mundial apontou-se que no ano de 2018 ocorreram 18 milhões de casos novos de câncer e 9,6 milhões de óbitos ${ }^{3}$.

Sua incidência e mortalidade têm aumentado, sendo previsto que o número de indivíduos doentes de câncer aumente cerca de $70 \%$ nas próximas duas décadas ${ }^{4}$. Apesar da evolução no tratamento ter permitido o acréscimo de sobrevida, em muitos casos, não é possível evitar efeitos secundários significativos e uma evolução crônica da doença, o que torna cada vez mais premente, a questão da adaptação da pessoa doente e da sua família 5 .

As Políticas Públicas geralmente priorizam os cuidados em ambiente ambulatorial ou domiciliar, visando reduzir intervenções desnecessárias, bem como, os custos hospitalares para as instituições de saúde. Com isso, o envolvimento da família torna-se integral, trazendo impactos desde o diagnóstico, passando pelo tratamento, pós-tratamento e tudo o que permeia vivenciar esta enfermidade ${ }^{6}$. A opção pela assistência domiciliar, demanda a presença de acompanhante para os cuidados diários da pessoa doente. Assim, essa demanda desafia a família a eleger um/a cuidador/a principal ${ }^{6}$, que será quem realizará atividades voltadas ao cuidado de saúde, assume a responsabilidade, oferece suporte e visa a melhoria da qualidade de vida da pessoa doente ${ }^{1,7}$.

São grandes os desafios encontrados por familiares ao assumir este papel. Surgem mudanças na vivência e atividades cotidianas, tendo que se adaptar a uma nova rotina cheia de tensões e preocupações ${ }^{8}$. Em alguns casos sem o devido conhecimento e treinamento prévios. Cuidar de familiar doente, pode levar ao desgaste físico e emocional que, se não for observado, poderá comprometer o cuidado e a saúde também do/a cuidador/a? .

Cuidadores/as familiares geralmente são parentes, parceiros/as ou amigos/as próximos que têm um relacionamento pessoal significativo com o/a familiar doente. Espera-se que cuidadores/as familiares auxiliem em todos os aspectos de sua vida, o que pode 
variar desde ajudar em atividades básicas de vida diária até fornecer apoio emocional, social e financeiro ${ }^{10}$. À medida que a doença progride e o/a familiar doente sob seus cuidados torna-se cada vez mais dependente, o/a cuidador/a tende a vivenciar uma sobrecarga $^{11}$, que afeta sua qualidade de vida, uma vez que cuidar de um familiar exige disponibilidade, tempo e dedicação ${ }^{6,12,13}$.

Este trabalho objetiva compreender a vivência do/a cuidador/a de familiar doente de câncer; conhecer quais aspectos são afetados em sua vida; e descrever as estratégias utilizadas para o enfrentamento das mudanças. Sugere-se que essa pesquisa possa contribuir trazendo luz aos desafios que cuidadores/as vivenciam durante o processo de adoecimento de familiar, desde as alterações na rotina até os reflexos psicológicos emocionais. Acredita-se que a possibilidade de compartilhar estratégias de adaptação possa beneficiar aos/as cuidadores/as.

\section{MÉTODO}

Este estudo, de abordagem qualitativa, revisou a literatura para identificar as produções científicas relacionadas a vivência de cuidadores/as de pessoas doentes de câncer. Optou-se pela realização de uma revisão integrativa, método que proporciona a síntese de conhecimento e a incorporação da aplicabilidade de resultados de estudos significativos na prática ${ }^{14}$. Percorreu-se seis etapas: formulação da questão de pesquisa, busca na literatura, categorização dos estudos, avaliação dos estudos incluídos, interpretação dos resultados e sintetização do conhecimento.

Para realizar a busca foram escolhidos quatro descritores de saúde: cuidador familiar (family caregiver); diagnóstico (diagnosis); câncer (cancer); cuidar (take care). Em seguida, definiram-se descritores e palavras de textos que exprimissem e ampliassem a abrangência destes três grupos de elementos. A combinação intragrupos foi feita utilizando o operador boleano OR, e para a combinação intergrupos foi usado o AND: ("cuidador" OR "cuidador familiar") AND (câncer OR "neoplasia”) (“diagnóstico" OR "diagnose") AND ("cuidar" OR "cuidado").

Efetivou-se uma busca na Base de dados eletrônicas: Scientific Electronic Li-brary Online (SciELO), Periódicos Eletrônicos de Psicologia (PePSIC), Centro Latino-Americano e do Caribe de Informação em Ciências da Saúde (BIREME/BVS) e Portal de Periódicos da Coordenação de Aperfeiçoamento de Pessoal de Nível Superior (CAPES).

Quanto aos critérios de elegibilidade, foram incluídos: estudos com população de pacientes e cuidadores/as, maiores de 18 anos de idade, indexados em bases de dados publicados em inglês, espanhol ou português, entre 2015 a 2020, e excluídos: estudos sem determinação de metodologia clara, teses e dissertações e publicações incompletas e repetidas. 


\section{RESULTADOS}

O resultado das buscas estão expostos conforme as bases no Quadro 1 e o obtido durante a seleção final está registrado no Quadro 2.

Quadro 1. Resultados da pesquisa, de acordo com o diagrama de fluxo PRISMA. Adaptado pela autora (2020).

\begin{tabular}{|c|c|c|}
\hline $\begin{array}{l}\text { Estudos Identificados por meio } \\
\text { de pesquisa no banco de dados } \\
\text { entre abril e julho de } 2020 .\end{array}$ & $\begin{array}{c}\text { Estudos excluídos após leitura } \\
\text { do resumo e aplicação dos cri- } \\
\text { térios de inclusão e exclusão: }\end{array}$ & $\begin{array}{c}\text { Estudos apropriados para } \\
\text { revisão segundo critérios } \\
\text { de inclusão e exclusão: }\end{array}$ \\
BVS: 8 & BVS: 2 & BVS: 6 \\
CAPES: 8 & SAPES: 5 & CAPES: 3 \\
SciELO: 6 & PePSIC: 0 & SciELO: 3 \\
PePSIC: 3 & TOTAL: $\mathbf{1 0}$ & PePSIC: 3 \\
TOTAL: $\mathbf{2 5}$ & TOTAL: $\mathbf{1 5}$ \\
\hline
\end{tabular}

Fonte: Dados da pesquisa (2020).

Quadro 2. Trabalhos incluídos na seleção final

\begin{tabular}{|l|l|l|l|l|l|}
\hline Fonte & Título & Autoria & Área & $\begin{array}{l}\text { Objetivo do } \\
\text { estudo }\end{array}$ & Ano \\
\hline SciELO & $\begin{array}{l}\text { Ser Cuidador de } \\
\text { Familiar com cân- } \\
\text { cer }\end{array}$ & $\begin{array}{l}\text { Ferreira MLM, } \\
\text { Mutro ME, } \\
\text { Conde CR, } \\
\text { Sanches Marin } \\
\text { MJS, Meneguin } \\
\text { S, Mazzetto } \\
\text { FMC. }\end{array}$ & Enfermagem & $\begin{array}{l}\text { Compreender a } \\
\text { experiência do } \\
\text { cuidador familiar } \\
\text { de paciente com } \\
\text { câncer }\end{array}$ & 2018 \\
\hline SciELO & $\begin{array}{l}\text { Sobrecarga no } \\
\text { cuidar e suas re- } \\
\text { percus-sões nos } \\
\text { cuidadores de } \\
\text { pacientes em fim } \\
\text { de vida: revisão } \\
\text { sistemática da lite- } \\
\text { ratura }\end{array}$ & $\begin{array}{l}\text { Delalibera } \\
\text { M, Presa J, } \\
\text { Barbosa A, } \\
\text { Leal I. }\end{array}$ & Psicologia & $\begin{array}{l}\text { Revisão siste- } \\
\text { mática da lite- } \\
\text { ratura sobre a } \\
\text { sobrecarga no } \\
\text { cuidar, os fatores } \\
\text { relacionados e } \\
\text { suas conse- } \\
\text { quências nos } \\
\text { cuidadores de } \\
\text { pacientes com } \\
\text { câncer avançado } \\
\text { em fim de vida } \\
\text { ou em CP. }\end{array}$ & 2015 \\
\hline
\end{tabular}




\begin{tabular}{|c|c|c|c|c|c|}
\hline SciELO & $\begin{array}{l}\text { Sentimentos de } \\
\text { Pacientes em Cui- } \\
\text { dados Paliativos } \\
\text { sobre Modifica=- } \\
\text { ções Corporais } \\
\text { Ocasiona-das pelo } \\
\text { Câncer }\end{array}$ & $\begin{array}{l}\text { Oliveira DAS, } \\
\text { Cavalcante } \\
\text { LSB, Carvalho } \\
\text { RT. }\end{array}$ & Psicologia & $\begin{array}{l}\text { Investigar os } \\
\text { efeitos psicológi- } \\
\text { cos das modifi- } \\
\text { cações corporais } \\
\text { decorrentes do } \\
\text { adoecimento } \\
\text { e tratamento } \\
\text { oncológico em } \\
\text { pacientes que } \\
\text { estão sob Cuida- } \\
\text { dos Paliativos. }\end{array}$ & 2019 \\
\hline CAPES & $\begin{array}{l}\text { Sobrecarga do } \\
\text { cuidador familiar: } \\
\text { a sobrecarga de } \\
\text { cuidar de pacien- } \\
\text { tes com câncer de } \\
\text { pulmão, de acordo } \\
\text { com o estágio do } \\
\text { câncer e a quali- } \\
\text { dade de vida do } \\
\text { paciente }\end{array}$ & $\begin{array}{l}\text { Borges EL, } \\
\text { Franceschini J, } \\
\text { Costa LHD, } \\
\text { Fernandes } \\
\text { ALG, } \\
\text { Jamnik S, } \\
\text { Santoro IL. }\end{array}$ & Medicina & $\begin{array}{l}\text { Avaliar o impacto } \\
\text { do estágio do } \\
\text { câncer de pul- } \\
\text { mão e da qua- } \\
\text { lidade de vida } \\
\text { (QV) dos pacien- } \\
\text { tes com câncer } \\
\text { de pulmão na } \\
\text { sobrecarga do } \\
\text { cuidador. }\end{array}$ & 2017 \\
\hline CAPES & $\begin{array}{l}\text { Cuidador e cui- } \\
\text { dado: o sujeito e } \\
\text { suas relações no } \\
\text { contexto da assis- } \\
\text { tência domiciliar }\end{array}$ & $\begin{array}{l}\text { Yavol IS, Cam- } \\
\text { pos EMP. }\end{array}$ & Psicologia & $\begin{array}{l}\text { Conhecer carac- } \\
\text { terísticas emo- } \\
\text { cionais e o con- } \\
\text { texto do trabalho } \\
\text { do cuidador do- } \\
\text { miciliar, bem } \\
\text { como o sentido } \\
\text { do cuidar para } \\
\text { esses sujeitos. }\end{array}$ & 2016 \\
\hline CAPES & $\begin{array}{l}\text { Nível de estresse } \\
\text { dos cuidadores de } \\
\text { pacientes com } \\
\text { câncer em fase } \\
\text { terminal }\end{array}$ & $\begin{array}{l}\text { Silva RKN, No- } \\
\text { gueira LCLT, } \\
\text { Lima SLR, Lo- } \\
\text { pes BB, Cha- } \\
\text { ves AFL. }\end{array}$ & Enfermagem & $\begin{array}{l}\text { Avaliar o nível } \\
\text { de estresse dos } \\
\text { cuidadores de } \\
\text { pacientes com } \\
\text { câncer em fase } \\
\text { terminal. }\end{array}$ & 2017 \\
\hline BVS & $\begin{array}{l}\text { Validação de } \\
\text { tecnologia para } \\
\text { autocuidado do fa- } \\
\text { miliar cuidador de } \\
\text { pacientes onco- } \\
\text { lógicos paliativos } \\
\text { domiciliares }\end{array}$ & $\begin{array}{l}\text { Vale JMM, Mar- } \\
\text { ques Neto AC, } \\
\text { Santana ME, } \\
\text { Mendes CP. }\end{array}$ & Enfermagem & $\begin{array}{l}\text { Validar o con- } \\
\text { teúdo de uma } \\
\text { cartilha para } \\
\text { subsidiar o auto- } \\
\text { cuidado de fami- } \\
\text { liares cuidadores } \\
\text { de pacientes em } \\
\text { cuidados paliati- } \\
\text { vos oncológicos } \\
\text { domiciliares. }\end{array}$ & 2019 \\
\hline
\end{tabular}




\begin{tabular}{|c|c|c|c|c|c|}
\hline BVS & $\begin{array}{l}\text { Autocuidado do } \\
\text { cuidador de adoe- } \\
\text { cidos em cuidados } \\
\text { paliativos oncoló- } \\
\text { gicos domiciliares }\end{array}$ & $\begin{array}{l}\text { do Vale JMM, } \\
\text { Marques Neto } \\
\text { AC, } \\
\text { Santos LMS, } \\
\text { Santana ME. }\end{array}$ & Enfermagem & $\begin{array}{l}\text { Conhecer as } \\
\text { necessidades de } \\
\text { autocuidado de } \\
\text { familiares cui- } \\
\text { dadores frente } \\
\text { ao cuidado de } \\
\text { adoecidos em } \\
\text { cuidados paliati- } \\
\text { vos oncológicos } \\
\text { domiciliares e } \\
\text { propor estra- } \\
\text { tégias a esses } \\
\text { cuidadores para } \\
\text { a realização do } \\
\text { autocuidado. }\end{array}$ & 2019 \\
\hline BVS & $\begin{array}{l}\text { Como posso aju- } \\
\text { dar? Sentimentos } \\
\text { e experiên-cias do } \\
\text { familiar cuidador } \\
\text { de pacientes on- } \\
\text { cológicos }\end{array}$ & $\begin{array}{l}\text { Figueiredo T, } \\
\text { Silva AP, Silva } \\
\text { RMR, Silva JJ, } \\
\text { Silva CSO, Al- } \\
\text { cântara DDF, } \\
\text { Souza LPS, } \\
\text { Souza AAM. }\end{array}$ & Interdisciplinar & $\begin{array}{l}\text { Compreender } \\
\text { os sentimentos } \\
\text { de familiares } \\
\text { cuidadores ao } \\
\text { enfrentarem o } \\
\text { diagnóstico, o } \\
\text { tratamento e a } \\
\text { evolução do cân- } \\
\text { cer em um ente } \\
\text { querido. }\end{array}$ & 2017 \\
\hline BVS & $\begin{array}{l}\text { Estratégias de co- } \\
\text { ping entre familia- } \\
\text { res de pacientes } \\
\text { oncológicos }\end{array}$ & $\begin{array}{l}\text { Fetsch CFC, } \\
\text { Portella MP, } \\
\text { Kirchner RM, } \\
\text { Gomes JS, } \\
\text { Benetti ERR, } \\
\text { Stumm EMF. }\end{array}$ & Enfermagem & $\begin{array}{l}\text { Identificar as } \\
\text { estratégias de } \\
\text { coping utilizadas } \\
\text { por familiares de } \\
\text { pacientes onco- } \\
\text { lógicos hospitali- } \\
\text { zados. }\end{array}$ & 2016 \\
\hline BVS & $\begin{array}{l}\text { O universo con- } \\
\text { sensual do cuida- } \\
\text { dor-familiar e sua } \\
\text { ancoragem } \\
\text { dentro do cuida- } \\
\text { do: um estudo de } \\
\text { representa-ções } \\
\text { sociais }\end{array}$ & $\begin{array}{l}\text { Silva SED, } \\
\text { Costa JL, Araú- } \\
\text { jo JS, Moura } \\
\text { AAA, } \\
\text { Cunha NMF, } \\
\text { Santos AL. }\end{array}$ & Enfermagem & $\begin{array}{l}\text { Analisar as re- } \\
\text { presentações } \\
\text { de familiares de } \\
\text { pacientes em } \\
\text { cuidados palia- } \\
\text { tivos. }\end{array}$ & 2018 \\
\hline BVS & $\begin{array}{l}\text { Busca por cuidado } \\
\text { oncológico: per- } \\
\text { cepção de pacien- } \\
\text { tes e familiares }\end{array}$ & $\begin{array}{l}\text { Oliveira JM, } \\
\text { Reis JB, } \\
\text { Silva RA. }\end{array}$ & Enfermagem & $\begin{array}{l}\text { Compreender a } \\
\text { busca por cuida- } \\
\text { do do câncer a } \\
\text { partir da percep- } \\
\text { ção de pacientes } \\
\text { e familiares/ } \\
\text { cuidadores. }\end{array}$ & 2018 \\
\hline
\end{tabular}




\begin{tabular}{|c|c|c|c|c|c|}
\hline PePSIC & $\begin{array}{l}\text { Avaliação do im- } \\
\text { pacto psicossocial } \\
\text { do diagnóstico } \\
\text { e tratamento do } \\
\text { câncer na vida de } \\
\text { familiares } \\
\text { cuidadores de pa- } \\
\text { cientes em regime } \\
\text { de internação } \\
\text { hospitalar }\end{array}$ & $\begin{array}{l}\text { Oliveira TR, } \\
\text { Souza JR. }\end{array}$ & Psicologia & $\begin{array}{l}\text { Avaliar o impacto } \\
\text { do processo de } \\
\text { cuidar de um } \\
\text { parente com } \\
\text { câncer durante o } \\
\text { período de inter- } \\
\text { nação hospitalar. }\end{array}$ & 2017 \\
\hline PePSIC & $\begin{array}{l}\text { Avaliação do bem- } \\
\text {-estar de cuidado- } \\
\text { res familiares de } \\
\text { adultos com neo- } \\
\text { plasia maligna no } \\
\text { âmbito domiciliar }\end{array}$ & $\begin{array}{l}\text { Oliveira WT, } \\
\text { Sales CA, Fer- } \\
\text { nandes CAM, } \\
\text { Haddad MCL. }\end{array}$ & Enfermagem & $\begin{array}{l}\text { Analisar o bem- } \\
\text {-estar de cuida- } \\
\text { dores familiares } \\
\text { de adultos com } \\
\text { neoplasias ma- } \\
\text { lignas no âmbito } \\
\text { domiciliar pelo } \\
\text { Questionário de } \\
\text { Avaliação do } \\
\text { Bem-Estar Glo- } \\
\text { bal. }\end{array}$ & 2015 \\
\hline PePISC & $\begin{array}{l}\text { Autoestima dos } \\
\text { cuidadores de } \\
\text { doentes oncoló- } \\
\text { gicos com capa- } \\
\text { cidade funcional } \\
\text { reduzida }\end{array}$ & $\begin{array}{l}\text { Moreira NS, } \\
\text { Sousa CS, Po- } \\
\text { veda VB, Turri- } \\
\text { ni RNT. }\end{array}$ & Enfermagem & $\begin{array}{l}\text { Avaliar a autoes- } \\
\text { tima de cuidado- } \\
\text { res de doentes } \\
\text { oncológicos com } \\
\text { capacidade fun- } \\
\text { cional reduzida. }\end{array}$ & 2015 \\
\hline
\end{tabular}

Fonte: Dados da pesquisa (2020).

\section{DISCUSSÃO}

A partir da leitura sistemática dos 15 textos selecionados, chegou se a quatro categorias que sintetizam os temas dos artigos e apontam para os objetivos delimitados neste estudo: o feminino e o papel de cuidadora, impactos da mudança de rotina do/a cuidador/a, à saúde mental do/a cuidador/a e estratégias de enfrentamento.

\section{O FEMININO E O PAPEL DE CUIDADORA}

Em sua maioria, o cuidado de uma pessoa que adoece de câncer é delegado as mulheres. Essa predominância é histórica, desde a antiguidade cabe à mulher o papel social de cuidar da família, do lar, assim como das pessoas que adoecem ${ }^{13}$. Se o papel social é responsável por determinar a função das pessoas dentro da sociedade ${ }^{15}$, este papel social associado ao feminino, passado de geração em geração, parece determinista ao designar a mulher como cuidadora ${ }^{16,17}$. Este padrão cultural é transmitido de forma "natural", por processos educacionais formais e informais ${ }^{18}$. 
Embora o papel da mulher na família e na sociedade tenha sofrido várias transformações ao longo das últimas décadas, em função da crescente participação feminina no mercado de trabalho, com reflexos inevitáveis na vida doméstica, a consolidação de novas possibilidades para a vida da mulher caracteriza-se como um processo complexo, marcado por avanços e retrocessos ${ }^{19}$. Ainda nos dias atuais ${ }^{20}$, se reafirma o lugar da mulher como cuidadora, da casa, da família e consequentemente dos que adoecem, inclusive sendo ela que se desloca ao ambiente hospitalar quando necessário.

Com a evolução da doença, a pessoa designada ao cuidado pode ficar cada vez mais atarefada, já que a pessoa o doente tende a ficar mais dependente de seus cuidados. Isso pode acarretar prejuízos físicos, sociais e emocionais, principalmente quando se trata de uma pessoa cuidadora que mantém laço afetivo com o/a familiar que está sob seus cuidados ${ }^{13,16}$.

Muitas vezes por assumir esse papel de cuidadora, a mulher deixa de realizar atividades cotidianas, como cuidar da própria feminilidade e saúde, ou então, as realiza com menor frequência. Ao cuidar de uma pessoa doente, a mulher muitas vezes coloca-a como prioridade e esquece-se de si mesma vivendo em função desta ${ }^{21}$.

\section{IMPACTOS NA MUDANÇA DE ROTINA DO/A CUIDADOR/A}

São muitos os impactos presentes na descoberta de que um membro da família tem uma doença como o câncer. Alterações significativas passam a ocorrer, interferindo na normalidade das condições físicas, psicológicas e sociais. Estas alterações podem afetar todas as pessoas da família, mas principalmente aquela que assume o papel de cuidador/a principal, ou seja, o que vai ficar diretamente responsável pelo cuidado da pessoa doente ${ }^{16}$

O cuidador/a principal acaba abdicando até mesmo da sua atividade profissional ${ }^{22}$. Este novo papel vai sendo assumido naturalmente em função das demandas diárias, contudo, nem sempre passa por uma escolha, ou discussão familiar quanto ao seu desejo e disponibilidade, não há muitas vezes, um acordo explícito entre familiares na escolha de quem irá prover os cuidados ${ }^{23}$.

Cuidar de familiar doente de câncer requer muita disposição, empenho, amor e compromisso. Entretanto, ainda que haja disposição e propósito, o cotidiano carregado de responsabilidades, as mudanças na vida e na rotina, inevitavelmente virão a intervir diretamente na qualidade de vida do cuidador/a ${ }^{23}$.

O tratamento de câncer é um caminho difícil, composto por frequentes intervenções cirúrgicas ou clínicas e múltiplas internações, e por grande estresse físico e emocional ${ }^{24}$. Ou seja, não importa o quão bem e independente o paciente esteja a pessoa quando 
recebe o diagnóstico, em algum momento necessitará muito de um/a cuidador/a para ajudá-la ao longo da trajetória da doença ${ }^{10}$.

A convivência entre cuidador/a e a pessoa com câncer, desenvolve muitos sentimentos opostos, ora compreensão e solidariedade, ora raiva, mágoa e frustração ${ }^{25}$. Presenciar o desconforto físico e emocional, e o pensamento constantemente direcionado para o/a familiar gravemente doente são alguns dos aspectos que contribuem para diminuir o bem-estar do/a cuidador/a ${ }^{17}$.

$\mathrm{O}$ ato de cuidar, para os familiares é marcado por sentimentos e significados ${ }^{24}$, como os encontrados nos relatos extraídos das pesquisas analisadas, a identificação foi codificada sendo que "E" corresponde a Entrevistado/a e a numeração os diferencia:

Pra mim a experiência de cuidar é tudo, é meu pai e eu gosto de ajudar. $(\mathrm{E} 12)^{24: s p}$

Minha experiência? Ah acho que é uma retribuição por tudo que ela fez por mim, e nesta minha experiência vejo como aprendizado é que a família se une $[\ldots] .(\mathrm{E} 11)^{24: s p}$

Ele voltou a ser uma criança, e eu a sua mãe [...] cuido com o maior carinho. $(E 3)^{24: s p}$

Porém, em alguns momentos, vivenciar o cuidado torna-se uma atividade dolorosa, resultando em sobrecarga, estresse e tristeza, neste caso, a obrigação de cuidar se expressa como uma função exaustiva ${ }^{26}$. Ao suportar a agonia do/a doente de câncer, o/a cuidador/a passa a compartilhar de sua dor física, desencadeando sofrimento ${ }^{17}$ :

Ele chora bastante, quer sair, trabalhar, a gente sabe que não pode, explica pra ele que não pode mais, corta o coração. $(E 12)^{24: ~} S P$

É duro nessa situação dele, agora, pior ainda, até porque os médicos disseram que não tem mais o que fazer, é só esperar [...]. (E 13) ${ }^{24: s p}$

Cuidadores/as exercem muita influência no bem-estar da pessoa a seus cuidados ${ }^{16}$, devido à proximidade afetiva, que geralmente existe, seu apoio tem elevada importância para obter uma melhor adaptação ao longo do tratamento oncológico. Cuidadores/as provavelmente estarão presentes em todos os momentos, desde o diagnóstico até o desfecho do processo terapêutico, interagindo nas experiências pelas quais passa a pessoa doente no dia a dia. Portanto, como as pessoas, a que cuida e a que recebe cuidado se relacionam afetivamente, aspectos subjetivos de uma tende a influenciar a outra ${ }^{16}$.

Assumir a posição de cuidador/a exige aprender a lidar com as ameaças e o medo de novos sintomas, internações e limitações vividas pela pessoa doente ${ }^{29}$. Em geral, cuida- 
dores/as se sentem sobrecarregados com a função, além de vivenciarem sentimentos de angústia, desgaste físico e emocional, também vivenciam muitas cobranças, sendo desafiado a lidar com os sentimentos do doente e de sua família, uma vez que conflitos familiares podem aumentar por conta da doença e as atividades de lazer tornam-se raras ou inexistentes ${ }^{27}$ :

Não é fácil [...] porque eu não aguento com ele, não tenho quem me ajude. Me dói as costas (E2) 24:sp.

Eu nunca pedi nada para ninguém, mas eu me vi assim, numa situação tão difícil, tive que pedir para um para outro, você me ajuda com isso, tudo é difícil [...]. (E14) 24:sp

Meu convívio social mudou muito. Devido eu cantar, eu saía muito, e tinha muitos amigos, mas, por causa dele, eu tive que parar, já que não tenho ninguém pra me ajudar, aí, eu fui perdendo muitas coisas e muitos amigos. $(E 5)^{26: 5}$

Eu cuido dele sozinha, sempre cuidei desde o início. Meus irmãos nem aparecem aqui. Acho que eles deveriam, pelo menos, ligar para saber como ele está, sabe? Mas, sou só eu mesma aqui no batente. Para te falar a verdade, eu sinto raiva deles. A gente briga muito por causa disso. Eu me estresso, choro, até adoeço. Às vezes, eu acho que não vou dar conta e dá vontade de desisti. (E5) 26:5

Os outros irmãos também deveriam, pelo menos, no final de semana que eu estou trabalhando, procurar me ajudar, mas eles nunca se preocuparam com a mamãe do jeito que era pra ser. Eles quase nem vêm aqui, só ligam de vez em quando. Eu finjo que não ligo, mas, no fundo, me dá raiva, sabe?. (E7) ${ }^{26: 5}$

A sobrecarga de cuidadores/as familiares de pacientes com câncer pode variar de acordo com o estágio da doença e pode depender de fatores relacionados à condição de cada paciente ${ }^{10}$. Tais cuidadores/as poderão vivenciar: isolamento social, transformações negativas nas relações, comprometimento de aspectos físicos e emocionais, ausência de momentos de lazer, até mudanças de hábitos alimentares ${ }^{24}$.

Estudos relacionados à interação social ${ }^{23}$ constatam que ao assumir o papel de cuidador/a, o tempo para lazer diminui ou se torna inexistente, e esta privação pode gerar tristeza e problemas com a autoestima:

Quase não saio de casa, eu cuido dele, né? Desde o começo. Eu cuido dele, então não posso viajar, eu nem penso. (E9) 24:sp 
Cuidadores/as também assumem a administração medicamentosa, monitora sintomas, exercício e mobilidade, contudo, a maioria não possui as habilidades necessárias e confiança para realizar tais tarefas, essas rotinas contribuem para o seu desgaste ${ }^{22,23}$.

\section{SAÚDE MENTAL DO CUIDADOR/A}

Dentre os diferentes aspectos afetados ao assumir o papel de cuidador/a de uma pessoa doente de câncer, os efeitos relacionados à saúde mental ganham destaque, pois enfrenta uma série de conflitos emocionais, seja pela sobrecarga, alteração da rotina, negligência de aspectos pessoais, seja por compartilhar os medos e sofrimento da pessoa doente ${ }^{10,22,24}$ :

Às vezes, eu sinto que estou adoecendo, então, são várias coisas ao mesmo tempo, você não precisa só estar bem fisicamente, né, que aparentemente todos nós estamos bem fisicamente, mas, psicologicamente, que é a pior parte. $(E 7)^{26: 5}$

Os/as familiares que cuidam de pacientes com uma doença grave, como o câncer enfrentam um trabalho pesado que os/as deixa emocionalmente esgotados/as, fisicamente exaustos/as e completamente subjugados/as ${ }^{28}$ :

Praticamente não me cuido, estou cuidando mais dele. Eu sei que eu tenho que me cuidar, mas, agora, ele é a prioridade. Às vezes, eu estou muito triste, com vontade de chorar, sem forças, mas eu tenho que passar para ele que ele está tudo bem e que ele vai ficar bem. (E1) 26:5

Eu deixei de cuidar de mim, da minha saúde. Não vou mais ao médico, não saio para passear, não estudo mais, não trabalho, não me cuido, sabe? Tem dias que a dedicação é tão grande que eu nem durmo, fico a madrugada toda do lado dela. Tem vezes que, quando chega no fim do dia, eu ainda nem tomei banho, só cuidando dela. (E4) $26: 5$

O/a cuidador/a é permeado/a por uma diversidade de sentimentos envolvidos na relação de cuidado, especialmente a impotência, que faz muitas vezes com que se sinta triste e acredite que a situação tende a ficar mais difícil'. A sensação de impotência vivenciada diante da dor e sofrimento do/a familiar doente, poderá predispor ao medo, estresse e ansiedade, fatores que impactam em sua saúde mental ${ }^{8,20}$ :

Um sentimento de tristeza, porque é um tratamento doloroso, né!? Ver a pessoa sentir dor e você não pode fazer nada, às vezes a gente se sente impotente. Então resumindo: não é fácil!. (E8) $)^{8: 37}$

Percebeu-se a correlação entre as emoções vivenciadas por doente e cuidador/a, à 
medida que quem está doente apresenta mais sintomas relacionados à depressão ou ansiedade. Por exemplo, o/a cuidador/a também tende a vivenciar essas emoções, desta forma o seu estado de humor sofre influência do estado de humor do/a familiar doente ${ }^{16}$.

Alguns sintomas são comuns a cuidadores/as: privação de sono, sentimento de impotência, desamparo, dificuldades financeira, isolamento social, dificuldades em conciliar rotinas medicinais com a rotina do/a familiar doente ${ }^{11}$. Essas vivências, somadas à falta de orientações adequadas para o manejo dos cuidados de saúde, repercutem impactando diretamente na qualidade de vida e predispondo a quadros de ansiedade, depressão ${ }^{23}$ :

O que sinto é uma grande ansiedade, uma mistura de nervosismo. Sinto medo, angústia, pois nunca sei o que irá acontecer amanhã. Cada dia é uma agonia, pois o meu tio está cada vez pior, tenho medo de receber a qualquer momento uma má notícia e temo que ele se acabe do meu lado. (E5)8:37

Estou cansada, estressada, pois há um balanço emocional muito grande na minha vida. Me sinto fraca, cansada, triste, a dor é muito grande. $(E 7)^{8: 37}$

Alguns cuidadores/as ficam clinicamente deprimidos/as e fazem uso de medicação para depressão, ansiedade e insônia duas ou três vezes mais do que o restante da população. Assim como, apresentavam algum nível de ansiedade e depressão já no início do tratamento e que o distress psicossocial, a depressão e a sobrecarga aumentaram com o declínio funcional do/a familiar doente e com a fase mais crítica da doença ${ }^{11}$.

Segundo o Inventário de Sintomas de Stress para Adultos $70 \%$ dos cuidadores chegam a uma fase de exaustão ${ }^{22}$. Ao vivenciar toda essa complexidade que envolve tristeza, insônia, estresse, depressão, ansiedade e, por vezes, doenças psicossomáticas, os cuidadores desenvolvem estratégias de apoio, que visem modos de lidar com a situação ${ }^{20}$.

\section{ESTRATÉGIAS DE ENFRENTAMENTO}

Dentre estas estratégias a espiritualidade/religiosidade $(E / R)$ se destaca no enfrentamento. $O$ apego à $E / R$, como fonte de superação de angústias e sofrimento, permite a cuidadores/as sentirem-se acolhidos/as e compreendido s/as no enfrentamento:

Sou uma pessoa que fica insegura, mas só confio mesmo é em Deus. Busco paz na igreja, assim, para mim é tudo, os irmãos oram, fazem orações. Estamos buscando confiança em Deus. $(E 7)^{8: 37}$

Durante o desenvolvimento da doença, a família constrói seus alicerces de apoio, principalmente à $E / R$, independentemente da religião, relatam acreditar em Deus. Através da fé essas pessoas alcançam uma maior percepção de bem-estar emocional, sentindo-se protegidas por um "ser maior", que as ajudam a superar dificuldades, como 
vemos nestes relatos ${ }^{8}$ :

A gente confia muito, busca muito conforto em Deus, porque isso é uma força fundamental. Aqui no hospital existem os médicos que estão conduzindo, mas à frente deles está Deus. (E8) 8:37

Mas busco forças dos céus, em Deus, na família, temos muita fé. (E6) 8:37

A E/R podem ser utilizadas como uma estratégia de fortalecimento e direcionamento da vida familiar. Referenciadas como práticas já vivenciadas e que são intensificadas com o diagnóstico do câncer, são citadas por familiares como instrumentos de força e resistência. Para eles/as a superação de cada etapa da doença é conferida à fé em uma energia maior que é um "Deus", o qual demonstra e aplica o seu poder de curar.

Também ganha destaque, referente às estratégias de enfrentamento, a orientação das equipes de saúde, em especial a partir de visitas domiciliares. Essa estratégia tem sido apontada como fator protetivo ao aperfeiçoar as habilidades do/a cuidador/a familiar $^{26}$. A segurança transmitida por profissionais passa credibilidade na atenção a pacientes e repercute no compartilhamento do cuidado. A possibilidade de atendimento domiciliar estabelece uma relação de confiança que resulta em maior tranquilidade ao/a cuidador/a familiar, evitando, muitas vezes, a necessidade de deslocamento a serviços de pronto atendimento ${ }^{30}$.

Essa atenção especializada em domicílio é motivo de gratidão, e o convívio diário tende a estreitar os vínculos entre o/a cuidador/a e a equipe de saúde. O bom relacionamento, a satisfação e a confiança dos/as cuidadores/as com os/as profissionais diante de situações difíceis fazem com que cuidador/a se sinta acolhido e amparado para dar continuidade às suas atividades ${ }^{30}$.

Se percebe que um dos sentimentos mais vivenciados por cuidadores/as é o de impotência, neste caso é possível observar a busca de alternativas e de planos com a finalidade de resolver o problema de forma efetiva e que beneficie pacientes. Cuidadores/as possivelmente se sentem na obrigação de enfrentar a situação de maneira positiva para que pacientes sintam e encarem a doença da forma mais natural possível, enquanto que eles/as também precisam se adaptar à nova situação de vida e ao ambiente que fará parte de sua rotina diária ${ }^{31}$. É visto que atitudes mais positivas, otimistas, flexíveis e diretas de lidar com os sentimentos envolvidos em situações estressantes, como o câncer, favorecem adaptações mais saudáveis e a redução do impacto do estresse no equilíbrio psicofisiológico ${ }^{31}$.

Muitos fatores se relacionam a maneira que o/a cuidador/a passará por essa experiência, destacando-se atributos pessoais, como saúde e energia, sistema de crenças, metas 
de vida, autoestima, autocontrole, conhecimento, capacidade de resolução de problemas, práticas de apoio sociais e a utilização de estratégias de coping (enfrentamento) ${ }^{13}$.

\section{CONSIDERAÇÕES FINAIS}

Este estudo reafirma a mulher no papel de cuidadora, aponta para o fato de que a escolha do/a cuidador/a principal nem sempre se trata de uma negociação dentro dos ambientes familiares. Que na maioria das vezes o cuidado acaba centralizado em uma única pessoa, a qual terá sua rotina radicalmente alterada. A sobrecarga e os desafios desta vivência trazem consigo, um risco aumentado para o desenvolvimento de quadros relacionados ao sofrimento psíquico. Também pode se constatar que, dentre as estratégias de enfrentamento empregadas por cuidadores/as, destaca-se a E/R e o apoio recebido pelas equipes de saúde, em especial a partir das visitas domiciliares.

Considera-se que o objetivo de compreender a vivência do/a cuidador/a de familiar doente de câncer foi alcançado, embora a pesquisa tenha enfrentado limitações relativas à identificação de estudos recentes dentro dos critérios de elegibilidade. Acredita-se que a realização deste estudo contribua para que estudantes e profissionais conheçam os desafios que um/a cuidador/a vivencia durante o processo de adoecimento de familiar, desde as alterações na rotina até os reflexos psicológicos emocionais desta vivência. Espera-se, ainda, que a possibilidade de compartilhar estratégias de enfrentamento possa beneficiar a cuidadores/as.

\section{REFERÊNCIAS}

1. Brasil. Ministério da Saúde. Câncer: sintomas, causas, tipos e tratamentos. Portal Ministério da Saúde. Saúde de A a Z [Internet]. 2021 [acessado 2021 fev. 22]. Disponível em: http://antigo.saude.gov.br/saude-de-a-z/cancer

2. Karkow MC, Girardon-Perlini NMO, Stamm B, Camponogara S, Terra MG, Viero V. Experience of families facing the revelation of the cancer diagnosis in one of its integrants. Rev Min Enferm. [Internet]. 2015 jul./set. [acessado 2021 fev. 22]; 19 (3): 747-751. doi: http://www.dx.doi.org/10.5935/14152762.20150056

3. Brasil. Ministério da Saúde. Instituto Nacional de Câncer José Alencar Gomes da Silva. INCA. Estimativa 2020: incidência de câncer no Brasil. Rio de Janeiro: INCA, 2019. 120p. [acessado 2021 fev. 22]. Disponível em: https://www.inca.gov.br/estimativa/introducao

4. Portugal. Ministério da Saúde. Direção-Geral da Saúde. Programa Nacional para as Doenças Oncológicas. Lisboa: Direção-Geral da Saúde, 2017 Set. [acessado 2021 fev. 22]. Disponível em: https://comum. rcaap.pt/bitstream/10400.26/22531/1/Programa\%20Nacional\%20para\%20as\%20Doen\%C3\%A7as\%20 Oncol\%C3\%B3gicas\%202017.pdf

5. Albergaria R, Amorim R. Caracterização dos utentes de uma unidade de psico-oncologia extra-hospitalar. Psic., Saúde \& Doenças [Internet]. 2018 dez. [acessado 2021 fev. 23]; 19 (3): 550-563. doi: http:// dx.doi.org/10.15309/18psd190307

6. Marchi JA, Paula CC, Girardon-Perlini NMO, Sales CA. Significado de ser- cuidador de familiar com câncer e dependente: contribuições para a paliação. Texto contexto - enferm. [Internet]. 2016 [acessado 2021 fev. 23]; 25 (1): e0760014. doi: https://doi.org/10.1590/0104-07072016007600014 
7.Gomes MLP, Silva JCB, Batista EC. Escutando quem cuida: quando o cuidado afeta a saúde do cuidador em saúde mental. Revista Psicologia e Saúde. Campo Grande.2018. [acessado 2021 fev. 23]. doi: http:// dx.doi.org/10.20435/pssa.v10i1.530

8. Figueiredo T, Silva AP, Silva RMR, Silva JJ, Silva CSO, Alcântara DDF, et al. How can I help? Feelings and experiences of the familiar caregiver of cancer patients. ABCS Health Sci. [Internet]. 2017 abr. 26 [acessado 2021 fev. 23]; 42 (1). doi: https://doi.org/10.7322/abcshs.v42i1.947

9. Maciel MGS. Cuidados Paliativos-Definição e Princípios. Parte 1 Introdução. Página 15. Conselho Regional de Medicina do Estado de São Paulo. 2008. [acessado 2021 fev. 23]. doi: https://edisciplinas.usp.br/ pluginfile.php/446028/mod_resource/content/1/Cuidados_Paliativos_CREMESP.pdf

10. Borges EL, Franceschini J, Costa LHD, Fernandes ALG, Jamnik S, Santoro IL. Sobrecarga do cuidador familiar: a sobrecarga de cuidar de pacientes com câncer de pulmão, de acordo com o estágio do câncer e a qualidade de vida do paciente. J. bras. pneumol. [Internet]. $2017 \mathrm{fev}$. [acessado 2021 fev. 23]; 43 (1): 18-23. DOI: https://doi.org/10.1590/s1806-37562016000000177

11. Delalibera M, Presa J, Barbosa A, Leal I. Sobrecarga no cuidar e suas repercussões nos cuidadores de pacientes em fim de vida: revisão sistemática da literatura. Ciênc. saúde coletiva [Internet]. 2015 set. [acessado 2021 fev. 23]; 20 (9): 2731-2747. DOI: http://dx.doi.org/10.1590/1413-81232015209.09562014.

12. Blanc LO, Silveira LMOB, Pinto, SP. Compreendendo as experiências vividas pelos familiares cuidadores frente ao paciente oncológico. Pensando fam [Internet]. 2016 [acessado 2021 fev. 23]; 20 (2): 132-148. Disponível em: http://pepsic.bvsalud.org/pdf/penf/v20n2/v20n2a10.pdf

13. Moura Fetsch CF, Pereira Portella M, Kirchner RM, Sonego Gomes J, Rieth Benett ER, Miladi Fernandes Stumm EMF. Estratégias de coping entre familiares de pacientes oncológicos. Rev. Bras. Cancerol. [Internet]. 2016 mar. 31 [acessado fev. 23]; 62 (1): 17-5. DOI: https://doi.org/10.32635/2176-9745.RBC. 2016v62n1.175

14. Souza MT, Silva MD, Carvalho R. Revisão integrativa: o que é e como fazer. Einstein [Internet]. 2010 mar. [acessado 2021 fev 23]; 8 (1): 102-106. DOI: https://doi.org/10.1590/s1679-45082010rw1134

15. Martins ES. Os papéis sociais na formação do cenário social e da identidade. Kínesis. 25 dez 2010;2(04):40-52. [acessado 2021 mar 01]. doi: https://doi.org/10.36311/1984-8900.2010.v2n04.4905

16. Oliveira TR, Souza JR. Avaliação do impacto psicossocial do diagnóstico e tra-tamento do câncer na vida de familiares cuidadores de pacientes em regime de internação hospitalar. Tempus, actas de saúde colet. [Internet]. 2017 mar. [acessado 2021 fev 23]; 11(1): 215-227. doi: http://dx.doi.org/10.18569/tempus. v11i1.2228

17. Oliveira WT, Oliveira WT, Sales CA, Fernandes CAM, Haddad MCL. Avaliação do bem-estar de cuidadores familiares de adultos com neoplasia maligna no âmbito domiciliar. Rev. Eletr. Enferm. [Internet]. 2015 jun. 30 [acessado 2021 fev. 23]; 17 (2): 340-9. doi: https://doi.org/10.5216/ree.v17i2.28714

18 Coelho EAC. Gênero, saúde e enfermagem. Rev. bras. enferm. vol.58 no.3 Brasília May/June 2005. [acessado 2021 mar 01]. DOI: https://doi.org/10.1590/S0034-71672005000300018

19. Coutinho SMS, Menandro PRM. Representações sociais do ser mulher no con-texto familiar: um estudo intergeracional. Psic. saber soc. [Internet]. Jul 2015 [acessado 2021 fev. 23]; 4 (1): 52-71. doi: https:// doi.org/10.12957/psi.saber.soc.2015.13538

20. SILVA RKN, Lima LC, Silva TN, Lima LR, Lopes BB, Chaves, AFL. Nível de estresse dos cuidadores de pacientes com câncer em fase terminal. Rev expr católic saúde, [Internet]. 2018 ago. [acessado 2021 fev. 23];2, (2): 53-61. DOI: http://dx.doi.org/10.25191/recs.v2i2.2116

21. Piolli KC, Decesaro MN, Sales CA. O (des)cuidar-se como mulher ao ser cuidadora do companheiro com câncer. Rev. Gaúcha Enferm. [Internet]. 2018 [acessado 2021 fev. 23]; 39: e2016-0069. doi: http:// dx.doi.org/10.1590/1983-1447.2018.2016-0069

22. Oliveira JM, Reis JB, Silva RA. Busca por cuidado oncológico: per-cepção de pacientes e familiares. Rev. enferm. [Internet]. abr. 2018 [acessado 2021 fev. 23]; 12 (4): 938-946. doi: https://doi.org/10.5205/ 1981-8963-v12i4a231359p938-946-2018 
23. Vale JMM, Marques Neto AC, Santana ME, Mendes CP. Validação de tecnologia para autocuidado do familiar cuidador de pacientes oncológicos paliativos domiciliares. Rev. Rene [Internet]. 2019 [citado 2021 Fev 23]; 20: e40957. doi: http://dx.doi.org/10.15253/2175-6783.20192040957

24. Ferreira MLSM, Mutro ME, Regiani CC, Sanches Marin MJ, Meneguin S, Moerbeck FMC. Ser cuidador de familiar com câncer. Cienc. enferm. [Internet]. Abril 2018 [acessado 2021 fev. 23]; 24: 6. doi: http:// dx.doi.org/10.4067/s0717-95532018000100206

25. Yavo IS, Campos EMP. Cuidador e cuidado: o sujeito e suas relações no con-texto da assistência domiciliar. Psic teoria prát. [Internet]. 2016 [acessado 2021 fev. 23]; 18 (1): 20-32. Disponível em: http:// pepsic.bvsalud.org/pdf/ptp/v18n1/02.pdf

26. Vale JMM, Marques Neto AC, Santos LMS, Santana ME. Autocuidado do cuidador de adoecidos em cuidados paliativos oncológicos domiciliares. Rev enferm.UFPE [Internet]. 2019 [acessado 2021 fev. 23]; 13: e235923. doi: https://doi.org/10.5205/1981-8963.2019.235923

27. Moreira NS, Sousa CS, Poveda VB, Turrini RNT. Autoestima dos cuidadores de doentes oncológicos com capacidade funcional reduzida. Esc. Anna Nery [Internet]. 2015 jun. [acessado 2021 fev. 23]; 19 (2): 316-322. Disponível em: https://www.scielo.br/j/ean/a/RNHHZH59nM5rCdb5zhx67nN/?format=pdf\&lan$\mathrm{g}=\mathrm{pt}$

28. Oliveira BP. Mulheres cuidadoras: percepção de mudanças pessoais relacionadas ao cuidar. [trabalho de conclusão de curso]. Brasília: Faculdade de Ceilândia/Universidade de Brasília, Curso de Enfermagem; 2015 [ acessado 2021 fev 22]. Disponível em: https://bdm.unb.br/bitstream/10483/14018/1/2015_BarbaradePaulaOliveira.pdf

29. Santos FHE, Porto IS. De Florence Nightingale às perspectivas atuais sobre o cuidado de enfermagem: a evolução de um saber/fazer. Esc. Anna Nery vol.10 no.3 Rio de Janeiro. 2006 Dez [acessado 2021 fev. 22]. doi: https://doi.org/10.1590/S1414-81452006000300025

30. Maffei B, Arrieira ICO, Ferreira RA, Cardoso DH. Estratégias de enfrentamento de cuidadores de pacientes em cuidados paliativos no domicílio. Psicol. teor. prat. [Internet]. 2019 [acessado 2021 fev. 22 ]; 21 (3): 303-322. doi: http://dx.doi.org/10.5935/1980-6906/psicologia.v21n3p303-322

31. Gonçalves LO, Ferreira CB, Zanini DS, Vasconcelos CLB, Gonçalves SSS. Coping em pacientes crônicos, cuidadores e profissionais de saúde. Rev. SPAGESP [Internet]. 2015 [acessado 2021 fev. 22]; 16 (1): 107-121. Disponível em: http://pepsic.bvsalud.org/pdf/rspagesp/v16n1/v16n1a09.pdf

RECEBIDO: $11 / 03 / 2021$

ACEITO: 13/07/2021 